\title{
Regularities in superplasticity of titanium alloys in relation to their initial structure and phase composition
}

\author{
I. V. Ratochka ${ }^{1}$, E. V. Naydenkin ${ }^{1,2, \dagger}$, O. N. Lykova ${ }^{1}$, I. P. Mishin ${ }^{1}$ \\ †nev@ispms.tsc.ru

\begin{abstract}
${ }^{1}$ Institute of Strength Physics and Materials Science SB RAS, 2/4 Akademicheskii Ave., Tomsk, 634055, Russia
${ }^{2}$ National Research Tomsk State University, 36 Lenin str., Tomsk, 634050, Russia
\end{abstract}

The effect of the initial structure and phase composition on superplastic properties of pseudo $\alpha$ (Ti-4Al-2V), $\alpha+\beta$ (Ti-6Al-4V) and near $\beta$ (Ti-5Al-5Mo-5V-1Cr-1Fe) titanium alloys was studied in the temperature range of $773-1223 \mathrm{~K}$. It was shown that in the coarse-grained $\mathrm{Ti}-4 \mathrm{Al}-2 \mathrm{~V}$ alloy superplasticity is not realized in the temperature range studied. It is assumed that this is due to the low concentration of $\beta$ stabilizing elements and difficult development of phase transformation that promote the conversion of the lamellar structure into a globular one. In the case of two other alloys with a coarse-grained structure a decrease in the yield stress and an increase in elongation to failure over $150 \%$ are observed at temperatures above $1073 \mathrm{~K}$. All the alloys with a fine-grained structure exhibit a superplastic flow with elongations to failure over $300 \%$ regardless of their phase composition. The formation of an ultrafine-grained structure in the alloys results in a decrease in the temperature of the beginning of the superplastic flow realization up to $823 \mathrm{~K}$ independently of the phase composition as compared with coarsegrained and fine-grained alloys. The $\beta$ phase volume fraction and the nature of its precipitation have a significant effect on the features of the development of a superplastic flow and the maximum values of the relative elongation to failure. This effect is apparently due to the stabilization of the ultrafine-grained state by the precipitations of the $\beta$-phase along grain boundaries (Ti-6Al-4V alloy) or the formation of a micro-duplex two-phase structure (near $\beta$ alloy).

Keywords: titanium alloys, ultrafine-grained structure, superplasticity, phase composition.

\section{Introduction}

At present titanium alloys, due to their high specific strength and corrosion resistance, are widely used in various industrial applications [1-3]. Numerous studies carried out previously have shown that after the formation of a globular fine-grained structure (grain size $d<10 \mu \mathrm{m}$ ) in $\alpha+\beta$ titanium alloys superplasticity (SP) is usually observed at temperatures above $1073 \mathrm{~K}$ (above $0.5 \mathrm{~T}_{\mathrm{m}}$ ) and deformation rates below $10^{-3} \mathrm{~s}^{-1}[4,5]$. Thus, to realize superplasticity the material must already have a prepared fine-grained globular structure. At the same time, one of the features of $\alpha+\beta$ titanium alloys is that they become superplastic under certain temperature-strain rate conditions without any special structure preparation $[4,6]$. The realization of such "natural" superplasticity is due to the high diffusion mobility of atoms close to the temperatures of phase transformations. So by the time of the onset of tensile testing or directly in the process of deformation a globular fine-grained structure has been or is formed in the alloys [4]. In addition, the features of the initial structure as well as the phase composition of the alloys can significantly affect the development of the plastic flow and the value of the relative elongation to failure [4, $7-9$ ]. In this connection, it is important to study practically the features of the evolution of the structural-phase state and the development of the plastic flow of titanium alloys under deformation in a wide range of elevated temperatures in relation to the initial state.
The refinement of the grain structure by severe plastic deformation (SPD) methods results in a shift in the temperature-strain rate interval of the development of SP in titanium alloys to the region of lower temperatures and/or higher strain rates [8-12]. The superplastic properties are not determined only by the grain size and the structural-phase state of an alloy but also by high nonequilibrium interfaces with increased diffusivity [8-12].

In a number of works $[4,8,12-14]$ the effect of the $\beta$ phase volume fraction on the SP properties was studied by the example of $\alpha+\beta$ titanium alloys. In [13] it was shown that the enhanced values of SP characteristics of the Ti-6Al-4V alloy were observed at the volume fraction of the $\beta$ phase of about $20 \%$. At the same time, if the value of the volume fraction of the $\beta$ phase right in the process of deformation is taken into account, then the ratio of $\alpha$ and $\beta$ phases for the VT6 and VT9 alloys under optimal SP conditions is $3: 2$ [4]. Further increase in the $\beta$ phase volume fraction results in a substantial decrease of SP properties, as can be seen from the example of near $\beta$ titanium alloys [4]. On the other hand, in works $[8,15,16]$ it was shown that high superplasticity values can be achieved with a much smaller volume fraction of the $\beta$ phase (less than $5 \%$ ) for titanium alloys with the ultrafinegrained (UFG) structure. However, the reasons for such a behavior of UFG titanium alloys have not been revealed. Moreover, at present superplasticity in near $\beta$ titanium alloys with the ultrafine-grained structure is practically not studied in the well-known literature. In this connection, the 
present paper aims at comparative studies of the effect of the initial grain structure and volume fraction of $\beta$-phase on the superplastic properties of titanium alloys with different contents of alloying elements in a wide range of deformation temperatures.

\section{Materials and experimental procedures}

The study was carried out through the examples of the following titanium alloys: pseudo $\alpha$-alloy Ti-4Al-2V, $\alpha+\beta$ alloyTi-6Al-4V and transition alloy Ti-5Al-5Mo-5V-1Cr-1Fe. The chemical compositions of the alloys are given in Table 1.

The ultrafine-grained structure in the alloys was processed by means of $a b c$ pressing of coarse-grained alloys with the change of the deformation axis [17] using IP-2000 press in the temperature range of $1073-723 \mathrm{~K}$ in billets with the dimensions of $25 \times 25 \times 40 \mathrm{~mm}^{3}$. The deformation per one pressing was approximately 0.5 , the total accumulated deformation in all cases was not less than 7 . The fine-grained structure was obtained by annealing the UFG alloys for 1 hour in the temperature range of $973-1073 \mathrm{~K}$. Tensile tests were carried out in vacuum at $10^{-2} \mathrm{~Pa}$ in a wide range of temperatures using a PV-3012M unit with the initial strain rate of $6.9 \times 10^{-3} \mathrm{~s}^{-1}$. Samples in the form of a double blade with the working base size of $5 \times 1.7 \times 0.8 \mathrm{~mm}^{3}$ were cut by the electric spark method in the direction perpendicular to the axis of the last pressing. Electron microscopy studies of thin foils were carried out using a JEM-2100 microscope at the accelerating voltage of $200 \mathrm{kV}$ at the Shared Use
Center NANOTEH of ISPMS SB RAS. The foils for electron microscopy were prepared by the standard method using a Mikron-103 jet polishing machine with an electrolyte of the following composition: $20 \% \mathrm{HClO}_{4}-80 \% \mathrm{CH}_{3} \mathrm{CO}_{2} \mathrm{H}$. The dimension of the grain-subgrain structure elements was determined using a dark-field image. Not less than 200 measurements were sampled. Structural studies of the surface of the samples after stretching were carried out by scanning electron microscopy using a Quanta 200 3D microscope with a tungsten cathode and an attachment for the analysis of diffraction of backscattered electrons (EBSD) by Pegasus. Phase composition studies were performed by the X-ray diffraction analysis by means of a Shimadzu XRD6000 diffractometer using $\mathrm{CuK \alpha}$ radiation equipped with a monochromator. Metallographic studies of the alloys studied were performed using an Olympus GX 71 microscope.

\section{Results and discussion}

As already noted above, the present work considers titanium alloys belonging to three different classes: pseudo $\alpha$ (Ti-4Al-2V) alloy, $\alpha+\beta$ (Ti-6Al-4V) alloy and near $\beta$ (Ti-5Al-5Mo-5V-1Cr- $1 \mathrm{Fe}$ ) alloy. All these alloys in the initial state had a coarse-grained lamellar structure and differed significantly from each other by the volume fraction of the $\beta$ phase (Table 2). The alloys in the fine-grained and ultrafine-grained states have a globular shape structure.

Fig. 1 shows the temperature dependences of the yield strength and relative elongation to failure of the alloys in

Table 1. Chemical composition of the titanium alloys under consideration.

\begin{tabular}{|c|c|c|c|c|c|c|c|c|c|}
\hline Alloy & $A l$ & $V$ & $M o$ & $F e$ & $C r$ & $C$ & $O$ & $N$ & $H$ \\
\hline Ti-4Al-2V & 4.9 & 2.1 & - & 0.08 & - & 0.003 & 0.11 & 0.008 & 0.001 \\
\hline Ti-6Al-4V & 6.5 & 3.8 & - & 0.08 & - & 0.005 & 0.17 & 0.003 & 0.003 \\
\hline Ti-5Al-5Mo-5V-1Cr-1Fe & 4.74 & 5.04 & 5.57 & 0.98 & 0.81 & - & 0.1 & - & - \\
\hline
\end{tabular}

Table 2. The average grain size and the volume fraction of the $\beta$-phase $\left(f_{\beta}\right)$ in titanium alloys.

\begin{tabular}{|c|c|c|c|c|c|c|}
\hline & \multicolumn{2}{|c|}{ Coarse-grained state } & \multicolumn{2}{c|}{ Fine-grained state } & \multicolumn{2}{c|}{ Ultrafine-grained state } \\
\cline { 2 - 7 } & $d_{\mathrm{av}}, \mu \mathrm{m}$ & $f_{\beta}, \%$ & $d_{\mathrm{av}}, \mu \mathrm{m}$ & $f_{\beta}, \%$ & $d_{\mathrm{av}}, \mu \mathrm{m}$ & $f_{\beta}, \%$ \\
\hline Ti-4Al-2V & 700 & $1-2$ & 6 & $1-2$ & 0.25 & $1-2$ \\
\hline$T i-6 \mathrm{Al}-4 \mathrm{~V}$ & 480 & $\sim 10$ & 7 & $\sim 10$ & 0.25 & 5 \\
\hline$T i-5 \mathrm{Al}-5 \mathrm{Mo}-5 \mathrm{~V}-1 \mathrm{Cr}-1 \mathrm{Fe}$ & 130 & 42 & 1.5 & 67 & 0.15 & 34 \\
\hline
\end{tabular}

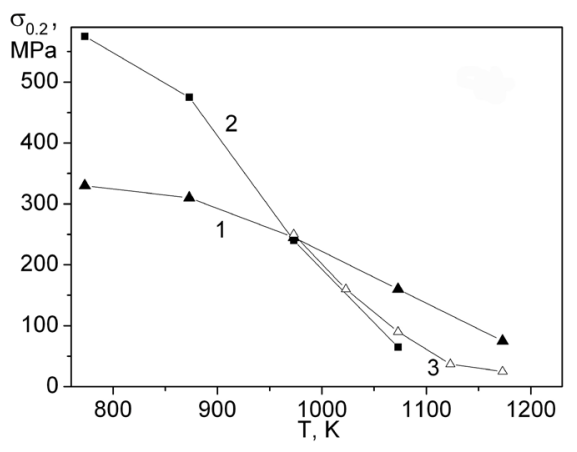

a

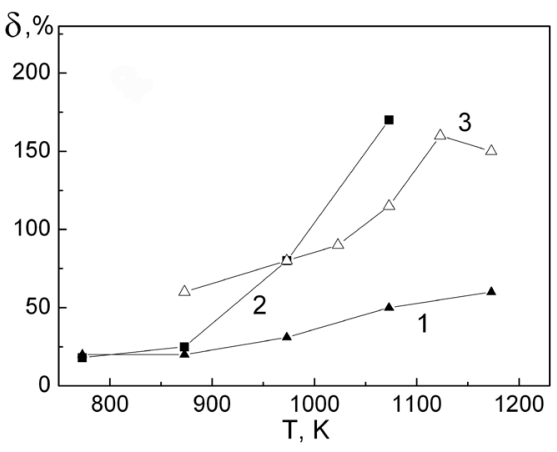

b

Fig. 1. Temperature dependence of the yield strength (a) and the relative elongation to failure (b) of coarse-grained titanium alloys: $1-$ Ti-4Al-2V;2 - Ti-6Al-4V;3 - Ti-5Al-5Mo-5V-1Cr-1Fe. 
the coarse-grained state. It is shown in Fig. 1a that the yield strength of the alloys doped in higher concentrations at temperatures above $973 \mathrm{~K}$ becomes significantly lower than that of pseudo $\alpha$ Ti-4Al-2V alloy. In this case, the ductility of the latter remains sufficiently low throughout the entire temperature range studied and does not exceed $60 \%$. At the same time, the elongation to failure of $\mathrm{Ti}-6 \mathrm{Al}-4 \mathrm{~V}$ and Ti-5Al-5Mo-5V-1Cr-1Fe alloys at temperatures above $1073 \mathrm{~K}$ exceeds $150 \%$ (Fig. 1b).

Assume that the superplastic flow is realized when the samples are elongated to fracture more than $100 \%$, then the the two latter alloys become superplastic under the considered conditions. The mechanism for realizing the superplastic flow in coarse-grained $\alpha+\beta$ titanium alloys (which the Ti-6Al-4V alloy belongs to) having the initial plate structure has been considered in detail by O. A. Kaibyshev with co-workers [4]. In particular, this paper shows that in $\alpha+\beta$ titanium alloys the lamellar structure can be transformed into the equiaxed fine-grained structure due to phase transformations and recrystallization processes. These processes can develop under heating and deformation conditions at temperatures close to the transus temperature.

As is seen from Fig. 1b, for Ti-4Al-2V alloy in the coarsegrained state the superplastic flow is not realized under the conditions considered in this paper. This is apparently due to the low concentration of $\beta$-doping additives in the alloy and the high temperature of the polymorphic transformation which for this alloy is about $1233-1253 \mathrm{~K}$ [3]. Due to these factors, the lamellar structure does not transform into a globular one,

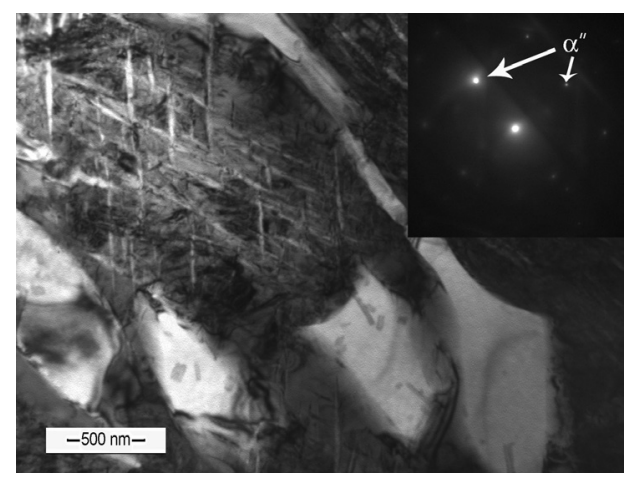

a which is necessary for the realization of superplasticity. At the same time, in the near $\beta$ alloy an active development of phase transformations can be expected under deformation in the temperature range of $1073-1173 \mathrm{~K}$. It is caused by the high concentration of $\beta$-stabilizing elements which reduce the transus temperature to $1123-1163 \mathrm{~K}$ [3]. The latter is assumed to result in the realization of the superplastic flow in the coarse-grained state of this alloy in a manner similar to that for Ti-6Al-4V alloy. Indeed, as is seen from the electron microscopic images (Fig. 2), the formation of new $\alpha$ or $\alpha$ "-phase particles is observed in Ti-5Al-5Mo-5V-1Cr-1Fe alloy with the coarse-grained structure after superplastic deformation by $100 \%$.

It should be noted that an additional thermomechanical treatment of the above alloy leads to a formation of a structural-phase state with a high volume fraction of the metastable $\left(\alpha^{\prime \prime}\right)$ phase and ductility increases up to $350 \%$ due to the activation of phase transformations and development of diffusion-controlled processes which affect grain boundary sliding (GBS) [18].

Presented in Fig. 3 is the dependence of the mechanical properties of fine-grained titanium alloys on temperature. One can see that the temperature dependence of the yield strength has a qualitatively similar character for all the alloys regardless of their phase composition. In the entire temperature range studied a significant drop in the yield strength of alloys is observed and the superplastic flow at temperatures $1073-1173 \mathrm{~K}$ is realized. At the same time, the relative elongation of the samples to failure reaches $300-400 \%$.

Fig. 2. The microstructure of the coarse-grained Ti-5Al-5Mo-5V-1Cr-1Fe alloy after $100 \%$ deformation at $1123 \mathrm{~K}$ : bright field image (a); dark field image of $\alpha$ "-phase (322) (b).
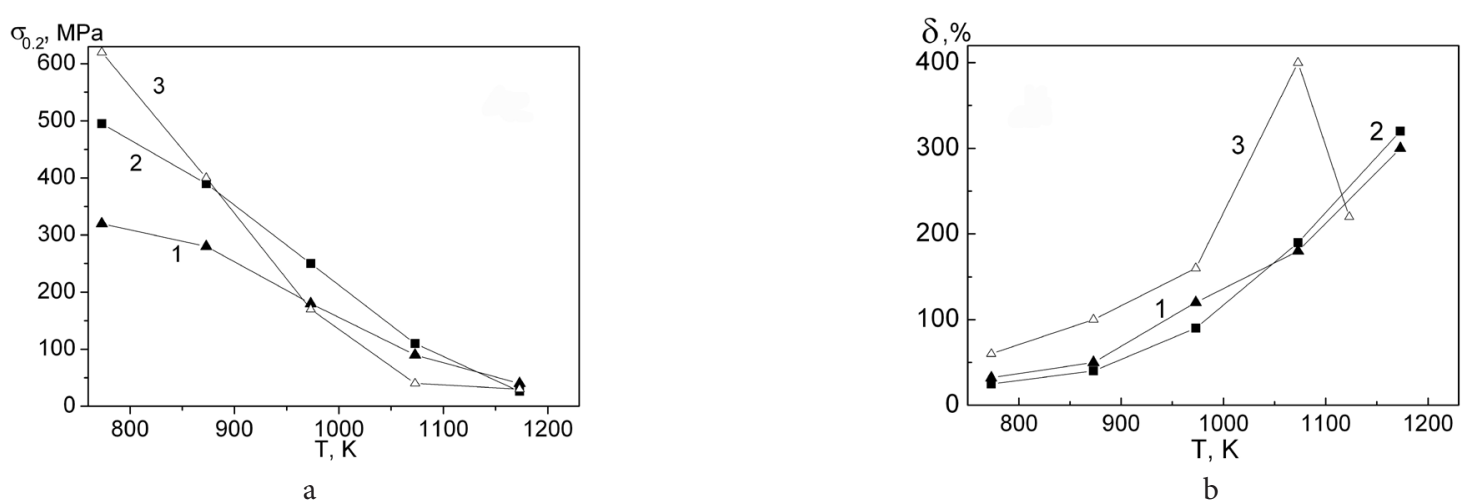

Fig. 3. Temperature dependence of the yield strength (a) and the relative elongation to failure (b) of fine grained alloys: $1-\mathrm{Ti}-4 \mathrm{Al}-2 \mathrm{~V}$; 2 - Ti-6Al-4V; 3 - Ti-5Al-5Mo-5V-1Cr-1Fe. 
However, from the dependences of the relative elongation on temperature shown in Fig. 3 it is evident that the $400 \%$ elongation is the maximum one for the near $\beta$ alloy. At the same time, for the two other alloys the maximum ductility apparently is not achieved. In addition, the average grain size of these alloys is much more than that of the near $\beta$ alloy (Table 2). This factor can significantly affect the elongation to failure. For instance, it was shown in [4] that the elongation of the Ti-6Al-4V alloy with the grain size of about $1 \mu \mathrm{m}$ is $1000 \%$ at the test temperature of $1173 \mathrm{~K}$. The data obtained in [4] demonstrated that the ductility of $\alpha+\beta$ titanium alloys under optimal SP conditions was usually higher than that of pseudo- $\alpha$ and near $\beta$ titanium alloys.

The formation of the ultrafine-grained structure in the titanium alloys considered in the present work results in a significant change in the mechanical characteristics in the entire temperature range studied. From the data shown in Fig. 4 it can be seen that in this case the temperature of the beginning of the superplasticity realization is reduced to $823 \mathrm{~K}$ regardless of the chemical and phase composition of the alloys.

In addition, a sharp drop in the yield stress, which is characteristic for superplastic deformation, is observed for all these alloys in the temperature range of $773-873 \mathrm{~K}$. At that, the increase of $\beta$ phase volume fraction results in a decrease of flow stress under the conditions of superplasticity (Fig. 3a). The study of the structural-phase state of titanium alloys considered in the present work after superplastic deformation under optimal conditions has shown that the state has a number of common features for all the alloys. In particular, a significant increase in the average grain size during superplastic deformation is observed (Table 3) in all the alloys. As is seen from the data in Table 3, the main grain growth occurs in the initial stages of deformation (up to $50-100 \%$ ). After that the grain size practically does not change, which apparently indicates the formation of new grains in the process of deformation (Fig. 2).

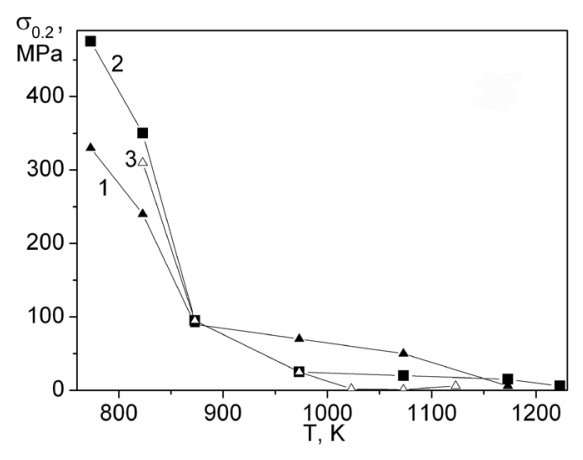

$\mathrm{a}$
In addition, the grains after deformation have an equiaxial shape. For example, the non- equiaxial coefficient for the Ti-4Al-2V alloy is approximately equal to 1.04. Also, a low dislocation density (about $10^{12} \mathrm{~m}^{-2}$ ) in the grain volume in all the alloys after the superplastic deformation under optimal conditions is observed. All of the experimental data listed above make it possible to assume that the main deformation mechanism in the ultrafine-grained alloys is grain-boundary sliding, while intergranular dislocation slip is an accommodation process. However, in this case it is impossible to make numerical estimations of the GBS contribution to the total deformation. As was noted above (Table 3), the formation of new grains takes place during deformation which results in the preservation of the average grain size regardless of the strain value.

The development of superplastic deformation and evolution of the structural-phase state of the alloys considered along with general features have significant peculiarities depending on their phase composition. In the pseudo $\alpha$ alloy $\mathrm{Ti}-4 \mathrm{Al}-2 \mathrm{~V}$ a noticeable grain growth with an increase in deformation temperature is observed. For example, an increase in the test temperature from 873 to $973 \mathrm{~K}$ results in grain growth from 0.87 to $1.24 \mu \mathrm{m}$ after a $100 \%$ strain. At the same time, in Ti-6Al-4V alloy after deformation under similar conditions at a temperature of $973 \mathrm{~K}$ the average grain size is almost half of that in Ti-4Al-2V alloy (0.7 vs. $1.24 \mu \mathrm{m})$. The average grain size of Ti-5Al-5Mo-5V-1Cr-1Fe alloy does not exceed $1 \mu \mathrm{m}$ even at a higher deformation temperature $(1073 \mathrm{~K})$. In addition, the nature of the distribution of the $\beta$ phase of the investigated alloys is different. In particular, the $\beta$-phase in $\mathrm{Ti}-6 \mathrm{Al}-4 \mathrm{~V}$ alloy is located predominantly on the boundaries of $\alpha$-phase normal for the tensile axis. In the Ti-5Al-5Mo-5V-1Cr-1Fe alloy $\alpha$ and $\beta$ phases form a micro-duplex structure (Fig. 5). As is seen from Fig. 5a, in the pseudo $\alpha \mathrm{Ti}-4 \mathrm{Al}-2 \mathrm{~V}$ alloy the second phase particles precipitated mainly in triple junctions of grain boundaries.

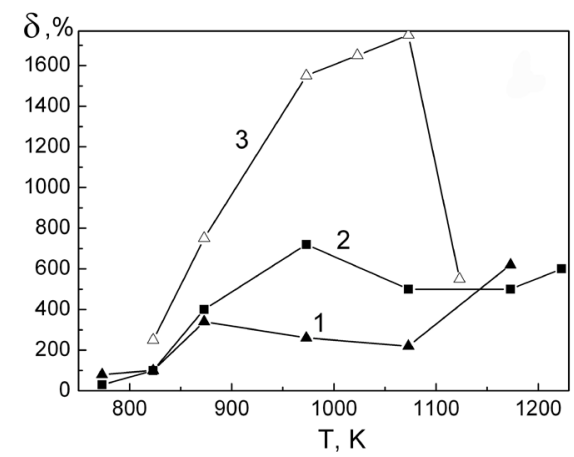

b

Fig. 4. Temperature dependence of the yield strength (a) and the relative elongation to failure (b) of UFG alloys: $1-\mathrm{Ti}-4 \mathrm{Al}-2 \mathrm{~V} ; 2-\mathrm{Ti}-6 \mathrm{Al}-4 \mathrm{~V}$; $3-\mathrm{Ti}-5 \mathrm{Al}-5 \mathrm{Mo}-5 \mathrm{~V}-1 \mathrm{Cr}-1 \mathrm{Fe}$ (curve 3 was obtained on samples with the gage of $2 \times 1 \times 0.8 \mathrm{~mm}^{3}$ ).

Table 3. The average grain size obtained by EBSD analysis in the dependence of strain under conditions of superplastic deformation.

\begin{tabular}{|c|c|c|c|c|c|}
\hline \multicolumn{2}{|c|}{ Strain $\varepsilon, \%$} & 0 & 50 & 100 & 200 \\
\hline \multicolumn{2}{|c|}{ Alloy } & \multicolumn{4}{|c|}{$d_{\mathrm{av}}, \mu \mathrm{m}$} \\
\hline$T i-4 A l-2 \mathrm{~V}$ & $\left(T_{\exp }-973\right)$ & 0.25 & & 1.24 & 1.27 \\
\hline$T i-6 A l-4 V$ & $\left(T_{\exp }-973\right)$ & 0.25 & & 0.71 & \\
\hline Ti-5Al-5Mo-5V-1Cr- $1 \mathrm{Fe}$ & $\left(T_{\exp }-1073\right)$ & 0.15 & 0.92 & 0.98 & 0.93 \\
\hline
\end{tabular}




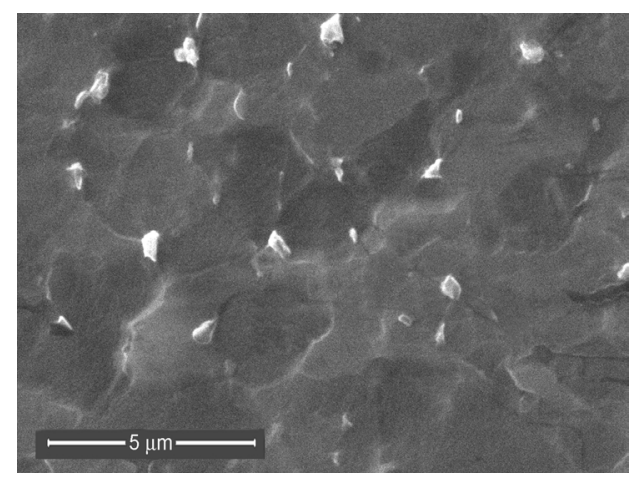

a

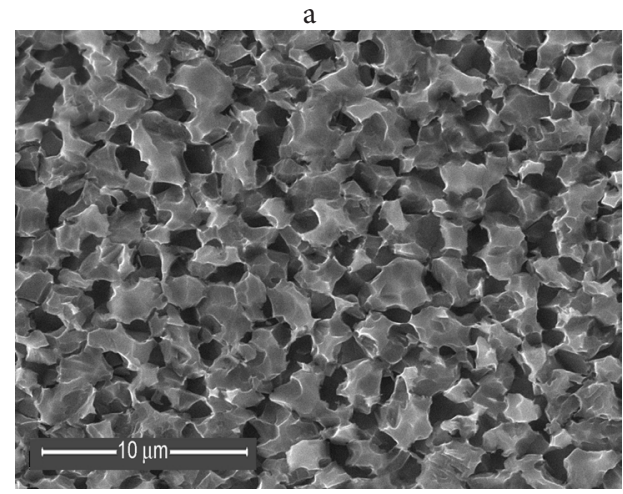

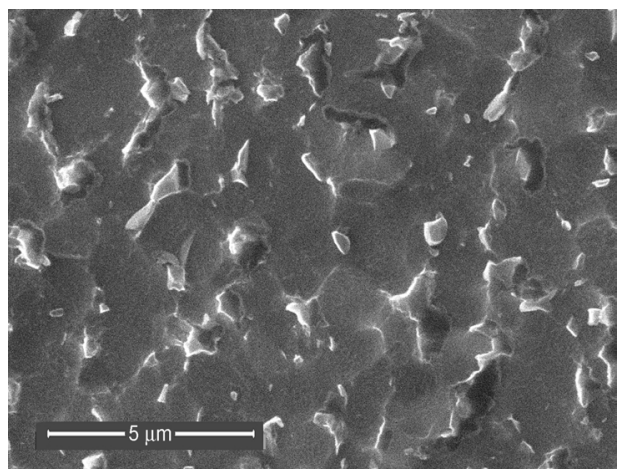

b

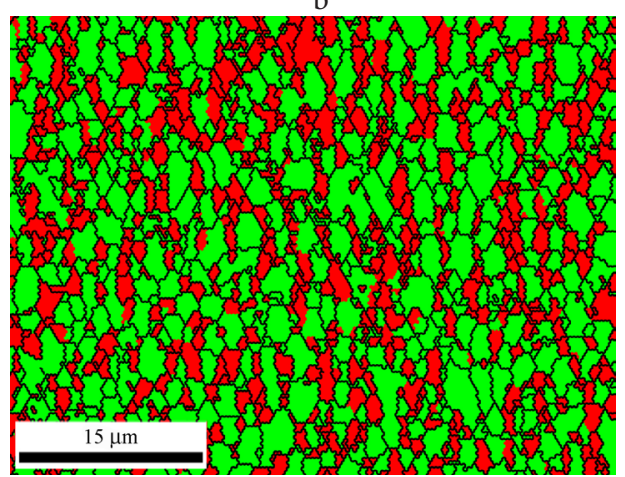

$\mathrm{d}$

Fig. 5. Microstructure of titanium alloys after superplastic deformation on 100\%: Ti-4Al-2V (deformation temperature $973 \mathrm{~K}$ ) (a); Ti-6Al-4V (deformation temperature $973 \mathrm{~K}$ ) (b); Ti-5Al-5Mo-5 V-1Cr-1Fe (deformation temperature $1073 \mathrm{~K}$ ) (c); EBSD map of phase distribution in Ti-5Al-5Mo-5 V-1Cr-1Fe alloy ( $\alpha$-phase highlighted by red color) (d). Tensile axis is horizontal.

It is evident that the alternation of $\alpha$ and $\beta$ phases in the bulk of the alloy leads to a suppression of the grain growth during heating and subsequent SP deformation (Table 3) $[4,13,19]$. In the case of a micro-duplex structure (Ti-5Al-5Mo-5V-1Cr-1Fe alloy), this stabilization is the most effective [20], which results in higher values of the relative elongation to failure under superplastic deformation (Fig. $4 \mathrm{~b}$ ). At the same time, the position of the second-phase particles in the triple junctions of Ti-4Al-2V alloy weakly inhibits the grain growth affecting its superplasticity. On the other hand, the revealed distribution of $\alpha$ and $\beta$ phases in the volume of the alloys studied seems to indicate a significant activation of grain-boundary diffusion fluxes of alloying elements. The presence of such fluxes can result in the development of a GBS in UFG alloys at relatively low temperatures $[8,21,22]$. It can be assumed that this process is one of the main reasons for the superplasticity realization at low temperatures $\left(0.4-0.55 T_{\mathrm{m}}\right)$.

Thus, the presented experimental data show that the formation of the UFG structure in the considered titanium alloys results in a decrease in the temperature of the beginning of the superplastic flow up to $823 \mathrm{~K}$ regardless of the phase composition and concentration of the alloying elements. However, the presence of the $\beta$-phase and the nature of its precipitation have a significant effect on both the width of the temperature range for the realization of superplastic flow and on the maximum values of the relative elongation to failure of the considered titanium alloys. It can be assumed that this effect is due to the enhanced stability of the ultrafine-grained structure under the conditions of the SP deformation of the titanium alloy Ti-5Al-5Mo-5V-1Cr-1Fe as a result of the formation of the micro-duplex two-phase structure.

\section{Conclusion}

The effect of the initial structure and phase composition on superplastic properties of the pseudo $\alpha$ (Ti-4Al-2V), $\alpha+\beta$ (Ti-6Al-4V) and near $\beta$ (Ti-5Al-5Mo-5V-1Cr-1Fe) titanium alloys has been studied in a wide temperature range $(773-1223 \mathrm{~K})$. It has been shown that in the coarse-grained Ti-4Al-2V alloy superplasticity is not realized during deformation in the temperature range studied. It is assumed that this is due to the low concentration of the $\beta$ stabilizing elements in this alloy and, as a consequence, to the complex development of phase transformations that promote the conversion of the lamellar structure into a globular one. In the case of two other alloys in the coarse-grained state a decrease in the yield stress and an increase in deformation to failure above $150 \%$ characteristic of the development of superplasticity are observed at temperatures above $1073 \mathrm{~K}$. In the alloys with a fine-grained structure the superplastic flow with elongations to failure above $300 \%$ is realized for all the alloys regardless of their phase composition.

It has been established that the formation of an ultrafinegrained structure in the titanium alloys under consideration results in a decrease in the temperature of the beginning of superplasticity up to $823 \mathrm{~K}$ regardless of the phase composition and concentration of the alloying elements. This may be due to the activation of a diffusion-controlled grain-boundary sliding in the case of nonequilibrium interfaces in materials obtained by the effect of severe plastic deformation. At the same time, the volume fraction of the $\beta$-phase and the nature of its precipitation have a significant effect on the features of the development of the superplastic flow and the maximum 
values of the relative elongation to failure of the titanium alloys. Apparently, this effect is due to the stabilization of the ultrafine-grained state in alloys due to the precipitation of the $\beta$-phase along the grain boundaries or the formation of a micro-duplex two-phase structure.

Acknowledgements. The work was carried out within the Fundamental Research Program of the State Academies of Sciences for 2013-2020, direction of research III.23, with partial financial support of RFBR (Grant No. 18-08-00452).

\section{References}

1. M. Peters, C. Leyens. Titanium and Titanium Alloys: Fundamentals and Applications. Wiley-VCH, Weinkeim, Germany (2003) 513 p.

2. V.N. Moiseyev. Titanium Alloys. Russian Aircraft and Aerospace Applications. CRC Press, New York (2005) $216 \mathrm{p}$.

3. A. A. Ilyin, B. A. Kolachev, I.S. Polkin. Titanium Alloys. Composition, Structure, Properties. Reference Book. Moscow, VILS-MATI (2009) 520p. (In Russian)

4. O.A. Kaibyshev. Sverkhplastichnost' Promyshlennykh Splavov (Superplasticity of Commercial Alloys). Moscow, Metallurgia (1984) 264 p. (in Russian)

5. T.G. Nieh, J. Wadsworth, O.D. Sherby. Superplasticity in Metals and Ceramics. Cambridge University Press, Cambridge (1997) 287p.

6. S.S. Bkhattacharya, O.I. Bylya, R.A. Vasin, K.A. Padmanabhan. Mechanics of Solids. 44-6, 951 (2009). DOI: 10.3103/S0025654409060120

7. O.A. Kaibyshev, R.Z. Valiev. Grain boundaries and metal properties. Moscow, Metallurgia (1987) 214p. (in Russian)

8. Yu.R. Kolobov, R.Z. Valiev, G.P. Grabovetskaya, A.P. Zhilyaev, E. F. Dudarev, K. V. Ivanov, M. B. Ivanov,
O. A. Kashin, E. V. Naydenkin. Grain boundary diffusion and properties of nanostructured materials. Cambridge Int Sci Publ. (2007) 236p.

9. E. V. Naydenkin, I. V. Ratochka, I. P. Mishin, O. N. Lykova, N. V. Varlamova. Journal of Materials Science. 52 - 8, 4164 (2017). DOI: 10.1007/s10853-016-0508-1

10. M. A. Meyers, A. Mishra, D. J. Benson. Prog Mater Sci. 51, 427 (2006). DOI: 10.1016/j.pmatsci.2005.08.003

11. R.Z. Valiev, A.P. Zhilyaev, T.G. Langdon. Bulk nanostructured materials: fundamentals and applications. Wiley, New Jersey (2013) 456 p.

12. H. Matsumoto, K. Yoshida, S-H. Lee, Y. Ono, A. Chiba. Mater Let. 98, 209 (2013). DOI: 10.1016/j.matlet.2013.02.033

13. T. Seshacharyulu, S.C. Medeiros, W.G. Frazier, Y.V.R.K. Prasad. Mater Sci Eng A. 284, 184 (2000). DOI: 10.1016/S0921-5093(00)00741-3

14. E. Alabort, P. Kontis, D. Barba, K. Dragnevski, R.C. Reed. Acta Mat. 105, 449 (2016). DOI: $10.1016 /$ j.actamat.2015.12.003

15. I. Ratochka, O. Lykova, I. Mishin, E. Naydenkin. Mater Sci Eng A. 731, 577 (2018). DOI: 10.1016/j.msea.2018.06.094

16. M. Ashida, P. Chen, H Doi, Y. Tsutsumi, T. Hanawa, Z. Horita. Mater Sci Eng A. 640, 449 (2015). DOI: $10.1016 /$ j.msea.2015.06.020

17. Patent RF No.2388566, 22.07.2008. (in Russian)

18. E. V. Naydenkin, I. V. Ratochka, I. P. Mishin, O. N. Lykova, N. V. Varlamova. Russian Physics Journal. 59, 397 (2016).

19. M. Meier, D. Lesuer, A. Mukherjee. Mater. Sci. Eng. A. 154, 165 (1992). DOI: 10.1016/0921-5093(92)90342-X

20. O. A. Kaibyshev, S. N. Faizova, A. F. Hairullina. Acta Mat. 48, 2093 (2000). DOI: 10.1016/S1359-6454(00)00039-2

21. Yu. R. Kolobov, I. V. Ratochka. Mater Sci Eng A. 410 - 411, 468 (2005). DOI: 10.1016/j.msea.2005.08.116

22. E. F. Dudarev, G.P. Pochivalova, Yu. R. Kolobov, E. V. Naydenkin, O.A. Kashin. Mater Sci Eng A. 503, 58 (2009). DOI: 10.1016/j.msea.2008.02.057 